\title{
Электронные микроскопы давно перестали быть экзотикой на производстве
}

Рассказывает генеральный директор ООО «ДжЕОЛ (РУС)» К. Саито

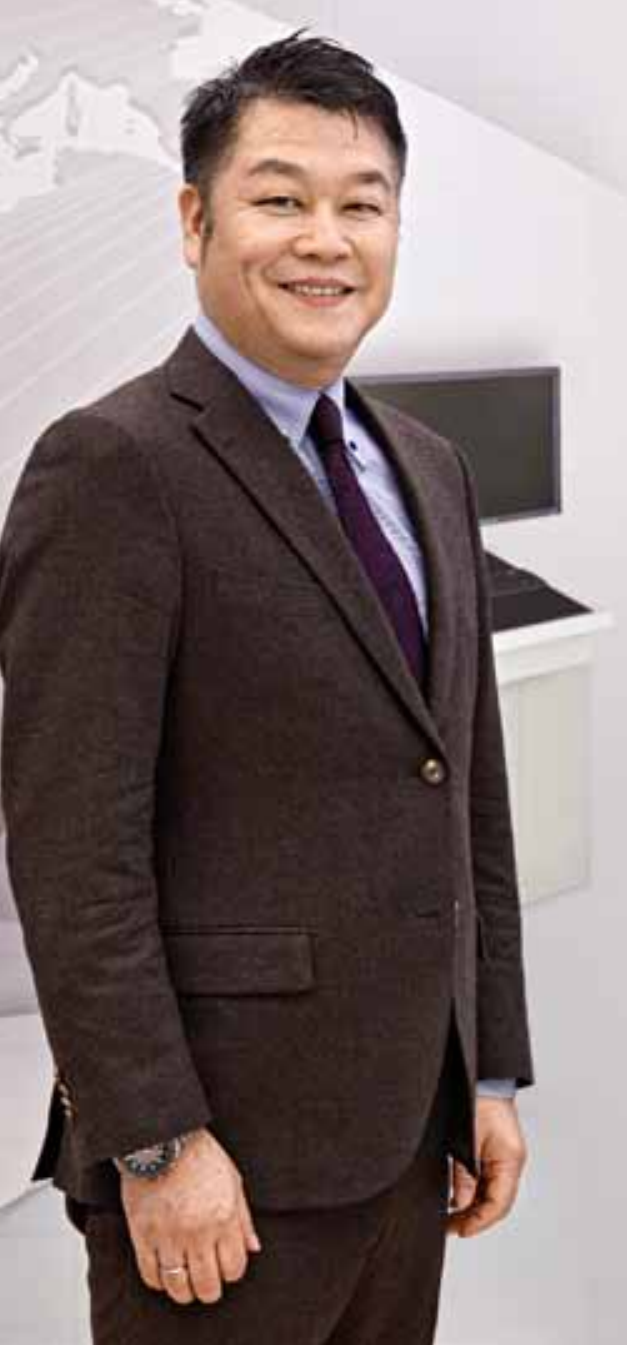

Японская компания JEOL Ltd. - один из мировых лидеров в области разработки и производства электронных микроскопов, рентгеновских и Оже-электронных микроанализаторов, спектрометров и другого аналитического оборудования - присутствует на рынке нашей страны с середины прошлого века. Ее оборудование применяется в университетах и институтах, занимающихся исследованиями в различных областях науки и техники, а также на производствах, в том числе в электронной отрасли. Кроме того, холдинг JEOL, в который входит JEOL Ltd., производит и другое оборудование, ряд которого специально предназначен для электронной промышленности.

Об истории работы JEOL Ltd. в России, использовании ее оборудования в производстве электроники и влиянии на потребность в нем современных требований к электронной аппаратуре, а также о том, как оборудование JEOL способно помочь российским производителям электроники в обеспечении качества и конкурентоспособности их продукции, нам рассказал Кэнтаро Саито (Kentaro Saito), генеральный директор ООО «ДЖЕОЛ (РУС)» - компании, представляющей JEOL Ltd. на российском рынке.

Господин Саито, история взаимоотношений компании JEOL с Россией уходит своими корнями еще в советский период. Как менялся бизнес JEOL в России в последние годы?

Действительно, JEOL долгое время работает на российском рынке. Первая поставка оборудования компании в вашу страну состоялась еще в 1959 году. Это был электронный микроскоп JЕМ-5G. В 1960 году было создано Московское представительство JEOL Ltd.

В общей сложности в Советский Союз было поставлено более 700 единиц оборудования нашей компании. Однако в конце 1980-х востребованность установок для исследовательских институтов и лабораторий и высокотехнологичных производств стала падать, и наши представительства в Москве и киеве были закрыты.

Ситуация стала выправляться к 2005 году, и тогда компания JEOL Ltd. снова открыла Московское представительство. С этого момента продажи нашего оборудования в России стали расти. В 2010 году было созДано ООО «ДЖЕОЛ (РУС)».

К сожалению, в 2014 году вновь наступил непростой период, и последние пять лет наши продажи 
на российском рынке были не столь активными, как хотелось бы. Но тем не менее, в течение последних двух лет мы наблюдаем рост спроса на оборудование данного типа. Так что признаки улучшения состояния рынка для нас есть, и мы смотрим на текущее положение позитивно.

\section{Оборудование какого типа преобладает среди поставленного JEOL в нашу страну?}

В основном это установки для исследований, в том числе растровые и просвечивающие электронные микроскопы высокого и сверхвысокого разрешения, электронно-зондовые рентгеновские и Оже-электронные микроанализаторы, другое аналитическое оборудование. В России всегда было много научных организаций, исследовательских институтов, работающих в области материаловедения, химии, физики, биологии, геологии и смежных дисциплинах. Именно они были и остаются нашими основными заказчиками в вашей стране. среди российских организаций, использующих наши установки, - научноисследовательские институты, как входящие в систему РАН, так и ведомственные, многие предприятия черной и цветной металлургии, геологоразведки и геологодобычи, почвоведения, авиастроения. Круг отраслей очень широк.

Кроме того, наши системы применяются в музеях, пользуются популярностью у искусствоведов, реставраторов.

\section{Взаимодействует ли ваша компания с россий- скими вузами?}

Конечно, мы уделяем большое внимание взаимодействию с высшим образованием. Очень важно, чтобы студенты, закончив вуз, были готовы применять современные средства исследования в своей профессиональной деятельности.

В частности, у нас уже довольно давно сложились хорошие отношения с МГУ им. М.В.Ломоносова. Мы поставили в этот университет порядка 30 установок.

Еще один пример - зеленоградский МИЭТ, в котором работает несколько наших современных растровых электронных микроскопов.

Среди наших клиентов также МФТИ, МИФИ, МИРЭА, МИСИС, УГАТУ, НГУ, СПбГУ, ННГУ И многие другие университеты и институты.

Где находит применение оборудование JEOL в электронной отрасли?

В Японии и многих других странах с развитой высокотехнологичной промышленностью электронная отрасль является нашим основным рынком. Среди компаний, которые достаточно широко применяют оборудование JEOL, - такие известные игроки рынка производства электроники, как Mitsubishi, Panasonic, Siemens, GE, TSMC, Samsung, LG и др. Я думаю, что подавляющее большинство компаний, чьи имена на слуху, использует наше оборудование.

Сфера применения электронных микроскопов и аналитического оборудования в производстве электроники очень широка. Она охватывает как передовые исследования в области новых материалов и структур, которые уже давно достигли нанометровых масштабов, так и серийное производство, где эти установки используются для контроля качества, поиска дефектов и выявления их первопричин, подтверждения того, что технологический процесс не выходит за допустимые рамки. Наши системы применяются как на промежуточных стадиях техпроцесса, так и при выходном контроле, а также для мониторинга процесса, подтверждения качества и надежности продукции, арбитражного контроля.

В кристальном производстве, например, электронные микроскопы могут быть практически незаменимым инструментом, учитывая размеры структур современных интегральных схем. Оборудование данного типа находит применение и в производстве дисплеев, аккумуляторов, и при оценке качества печатных плат, и для анализа соединений.

\section{Сфера применения электронных}

\section{микроскопов и аналитического оборудования в производстве электроники охватывает как передовые исследования в области новых материалов и структур, так и серийное производство}

Еще одна важная область применения электронных микроскопов - выявление дефектов элементов точной механики, которые тоже часто входят в состав электронных устройств.

За последнее время в мировой электронной промышленности очень сильно выросли требования к качеству и надежности продукции: электроника проникает во многие сферы деятельности людей и часто от нее критически зависит их безопасность. Как следствие растут и требования к производственному контролю, а средства такого контроля, в частности электронные микроскопы, становятся более востребованы, что мы явно ощущаем на нашем опыте. 
Есть ли специфика у электронных микроскопов, предназначенных для кристального производства?

Да, это оборудование обладает определенными особенностями. Во-первых, полупроводниковые пластины обрабатываются в помещениях высокого класса чистоты и даже в этих условиях они перемещаются между оборудованием в герметичных кассетах, исключающих контакт с воздухом произ водственных помещений. Поэтому и контрольное оборудование должно иметь возможность загруз ки и выгрузки таких кассет. Во-вторых, поле обзора электронного микроскопа достаточно узкое в сравнении с размерами пластины, поэтому для выполнения точных измерений необходимо прецизионное позиционирование и специальное программное обеспечение обработки изображений. Есть и другие особенности.

Производством оборудования для кристального производства у нас занимается другая компания, входящая в холдинг JEOL. Однако поставка установок этого типа на российский рынок также возможна.

Помимо электронных микроскопов, какие решения для электронной промышленности есть у JEOL?

Я уже упоминал, что в производстве электроники находят применение различные аналитические установки. Кроме собственно растровых и просвечивающих электронных микроскопов, здесь можно выделить, например, спектрометры ядерного магнитного резонанса (ЯМР-спектрометры), которые позволяют получать информацию о молекулярном строении образцов. Наиболее широкое применение яМР-спектроскопия находит в химии и биологии, однако этот метод может использоваться и в электронике, например для высокоточного определения составов материалов, загрязнений ит.п.

\section{Использование электронно-} лучевой литографии позволяет получить разрешение при

\section{прямом экспонировании, намного превышающее то, которое удается достичь методами фотолитографии}

Также можно упомянуть Оже-электронные микроанализаторы, в области которых у JEOL есть системы, занимающие лидирующие позиции. Оже-спектроскопия - это метод электронной спектроскопии, основанный на анализе распределения по энергиям электронов, возникающих в результате Оже-эффекта.
Он позволяет выполнять элементный анализ слоя поверхности очень малой толщины - несколько нанометров. Оже-электронные микроанализаторы - уникальные высокотехнологичные приборы. В мире установлено всего несколько десятков таких систем нашей компании, причем три из них - в России.

Спектр аналитического и исследовательского оборудования JEOL очень широк: это и масс-спектрометры, и установки электронной и рентгеновской спектроскопии, и др.

Но предложениехолдинга JEOL для микроэлектронных производств не ограничивается приборами для контроля, исследований и аналитики. Taк, JEOL является одним из лидеров в области оборудования для электронно-лучевой литографии. Этот метод экспонирования при производстве полупроводниковых кристаллов широко применяется для изготовления фотомасок. Кроме того, он очень эффективен для прямого (безмасочного) экспонирования при создании передовых кристаллов микросхем в небольших количествах - от прототипов и единичных изделий до небольших партий. Метод может использоваться также для таких перспективных областей, как наноимпринтная литография и производство изделий фотоники.

Для изготовления больших серий кристаллов обычно используется фотолитография с применением фотомасок, потому что она обладает высокой производительностью. Однако из-за большой длины волны фотона и, как следствие, оптических эффектов, снижающих разрешение, в этом случае приходится прибегать к различным ухищрениям, таким как многомасочная литография. Даже использование экстремального ультрафиолета (EUV) с его относительно малой длиной волны позволяет преодолеть эту проблему лишь частично.

Использование электронно-лучевой литографии позволяет получить разрешение при прямом экспонировании, намного превышающее то, которое удается достичь методами фотолитографии. Это вытекает прежде всего из физических свойств данных частиц: даже длина волны покоящегося электрона (комптоновская длина волны) на несколько порядков меньше длины волны EUV-фотона, следовательно и такие эффекты, как дифракция, проявляются на гораздо меньших масштабах. Кроме того, электрон заряженная частица, поэтому ее движением можно достаточно просто управлять с помощью электрических и магнитных полей.

Однако для получения высокого разрешения и воспроизводимости геометрии рисунка на практике только физических свойств электрона недостаточно. Необходимо обеспечить высокую точность оборудования. 
Для иллюстрации приведу некоторые характеристики одной из систем электронно-лучевой литографии JEOL - JBX-6300FS с ускоряющим напряжением до 100 кВ. Она способна работать с пластинами диаметром до 200 мм и 5- и 6-дюймовыми масками. Диаметр пучка составляет 2,1 нм. Высокая точность позиционирования в этой установке обеспечивается с помощью прецизионной системы коррекции с 19-битным ЦАП с разрешением 0,125 нм и лазерного интерферометра с разрешением 0,6 нм. Результирующая точность позиционирования не хуже \pm 9 нм, а минимальная ширина линии не превышает 8 нм.

Помимо этого, данная система обладает высокой производительностью: ее максимальная частота сканирования составляет 50 МГц.

Другая система - JBX-9500FS - может работать с пластинами диаметром 300 мм, а ее частота сканирования еще выше - 100 МГц.

Еще один вид промышленного оборудования, на который хотелось бы обратить внимание, - мощные электронные пушки. Это источники электронного луча, позволяющие осаждать тонкие, толстые и многослойные пленки, в частности в производстве силовых полупроводниковых приборов, ПАВ-фильтров, МЭМС, светодиодных устройств и проч. Электронные пушки могут создавать защитные, проводящие пленки, пленки электродов, магнитные пленки в устройствах хранения информации.

Кроме того, мощные электронные пушки, например серии JEBG, применяются и для вакуумного плавления, в частности для рафинирования поликристаллического кремния для солнечных батарей.

Вы сказали, что для кристального производства электронные микроскопы практически незаменимы. Широко ли применяется подобное оборудование в других секторах производства?

Электронный микроскоп давно перестал быть экзотикой во многих областях, не только на полупроводниковых фабриках, но в том числе и на других производствах электронных изделий.

Однако в России на таких производствах не так много этих приборов. Основную долю российскихзаказчикOB JEOL составляют научно-исследовательские организации, но непосредственно на электронные производства наше оборудование поставлялось лишь в единичных случаях. Эта картина сильно отличается от Японии и других промышленно развитых стран, где наши заказчики распределены примерно поровну: 50\% составляют институты, университеты и другие организации, занимающиеся исследованиями, и 50\% - производственные компании.
Как вы считаете, с чем может быть связано это отличие России?

Я думаю, что одной из основных причин такого положения вещей является различие в структуре рынка. В России исследования в основном проводятся в крупных государственных научноисследовательских организациях, а производства это обычно относительно небольшие компании с ограниченным бюджетом, особенно если речь идет о частном бизнесе.

В сознании многих людей, в особенности производственников, электронные микроскопы и современное аналитическое оборудование - это сложные дорогостоящие приборы, предназначенные для исследовательских целей на самом передовом крае науки. Многие считают, что производственная компания просто не может позволить себе такое оборудование и что производству нужны другие средства может быть, не такие точные, но более быстрые и простые в применении.

\section{Такое представление об электронных микроско-} пах - заблуждение?

Отчасти. Если мы рассмотрим, допустим, просвечивающий электронный микроскоп, то он сам является достаточно недешевым прибором и, кроме того, требует комплекса оборудования для пробоподготовки и т. п.

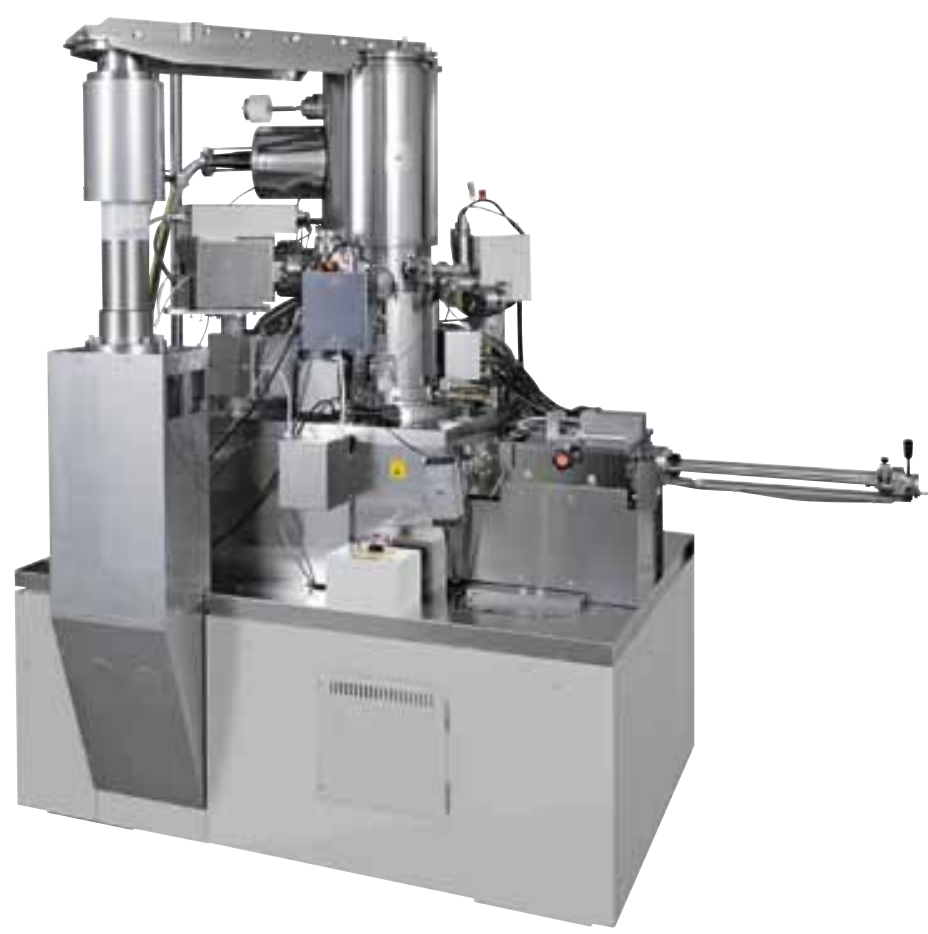

Система электронно-лучевой литографии JBX-6300FS 
Также следует отметить, что установки класса High-end, обладающие очень высокой точностью, разрешением, часто требуют высокой квалификации работающего с ними персонала именно в области микроскопии, а таких специалистов в производственной компании может не быть.

Но на производстве в основном применяются растровые микроскопы, а среди нашей линейки этих систем есть и небольшие и недорогие установки.

\section{Сейчас работа с большинством} наших электронных микроскопов, пожалуй, не сложнее, чем с обычным компьютером или смартфоном

Вообще, у электронных микроскопов есть несколько характеристик, достичь высокого уровня которых одновременно практически невозможно. Важными параметрами являются разрешение и контрастность изображения. Они сами по себе в определенном смысле находятся на разных чашах весов. Мы производим одни из лучших приборов по контрастности при достаточно высоком разрешении и, наоборот, по разрешению при достаточной контрастности. Но оба эти параметра сложно совместить с высокой производительностью, а именно производительность нужна на производстве в первую очередь. Поэтому мы также выпускаем высокопроизводительные микроскопы, контрастность и разрешение которых удовлетворяют запросы производства.

Можно сказать, что это особенность линейки растровых электронных микроскопов JEOL: многие наши конкуренты занимают некоторые промежуточные позиции, а наши микроскопы либо обладают передовыми характеристиками по качеству изображения, что нужно исследователям, либо предназначены для того, чтобы в максимальной степени удовлетворить потребности промышленных производств в производительности.

у нас даже есть настольные растровые электронные микроскопы - JCM-7000 Neoscope. Они занимают очень мало места и, кроме того, подключаются к обычной электросети. Это делает их очень хорошим решением для небольших компаний, если есть необходимость в получении изображений качества и разрешения, которые могут быть обеспечены только электронной микроскопией, или в быстром элементном анализе.

Но наиболее востребованными на производствах являются всё же системы с более высокими характеристиками, такие как автоэмиссионный растровый электронный микроскоп с катодом Шоттки JSM-7200F.

И для работы с такими, более простыми, микроскопами высокой квалификации не требуется?

Да, это очень важный момент. Настолько, что около трех-четырех лет назад мы внесли в наши приборы существенные изменения, направленные на то, чтобы сделать работу с ними как можно более простой. Сейчас работа с большинством наших микроскопов, пожалуй, не сложнее, чем с обычным компьютером или смартфоном. Для эффективного использования такого прибора не нужно быть высококвалифицированным специалистом именно в микроскопии. Кроме того, мы выпускаем инструкции для конкретных применений сложных приборов, чтобы упростить их эксплуатацию в производственных условиях. Пользуясь такими инструкциями, оператор может выполнять необходимые измерения, даже если он не обладает специальными знаниями в микроскопии, спектроскопии ит. п.

Мы проводим большую работу, чтобы донести до производственных компаний в России, что электронная микроскопия - это не какая-то элитная сфера, доступная только избранным. Применение этого метода контроля и анализа на современных мировых производствах - уже обычная, можно сказать, рутинная практика.

Недавно мы установили здесь, в нашем офисе в Москве, демонстрационный прибор - как раз такой простой настольный электронный микроскоп, JCM-7000 Neoscope. Наши потенциальные заказчики могут приехать к нам, попробовать поработать с ним, исследовать свой образец и убедиться, что это совсем не сложно.

Мы также проводим семинары в разных городах, куда привозим эту демонстрационную установку и где объясняем, как можно работать с ней и как ее применять на предприятиях. Так, в этом январе у нас состоялось такое мероприятие во Владивостоке, где собралось около 60 участников, половина из которых не обладала никаким опытом работы с электронными микроскопами, и они смогли убедиться, что в использовании этих приборов нет ничего сложного.

Эта работа приносит плоды: у нас всё больше запросов от российских производственных компаний и мы ведем ряд переговоров по вопросам поставки надежных и недорогих установок промышленного применения. 
JEOL $\bigcirc$

\section{JSM-7900F}

Полевой растровый электронный микроскоп

сверхвысокого разрешения

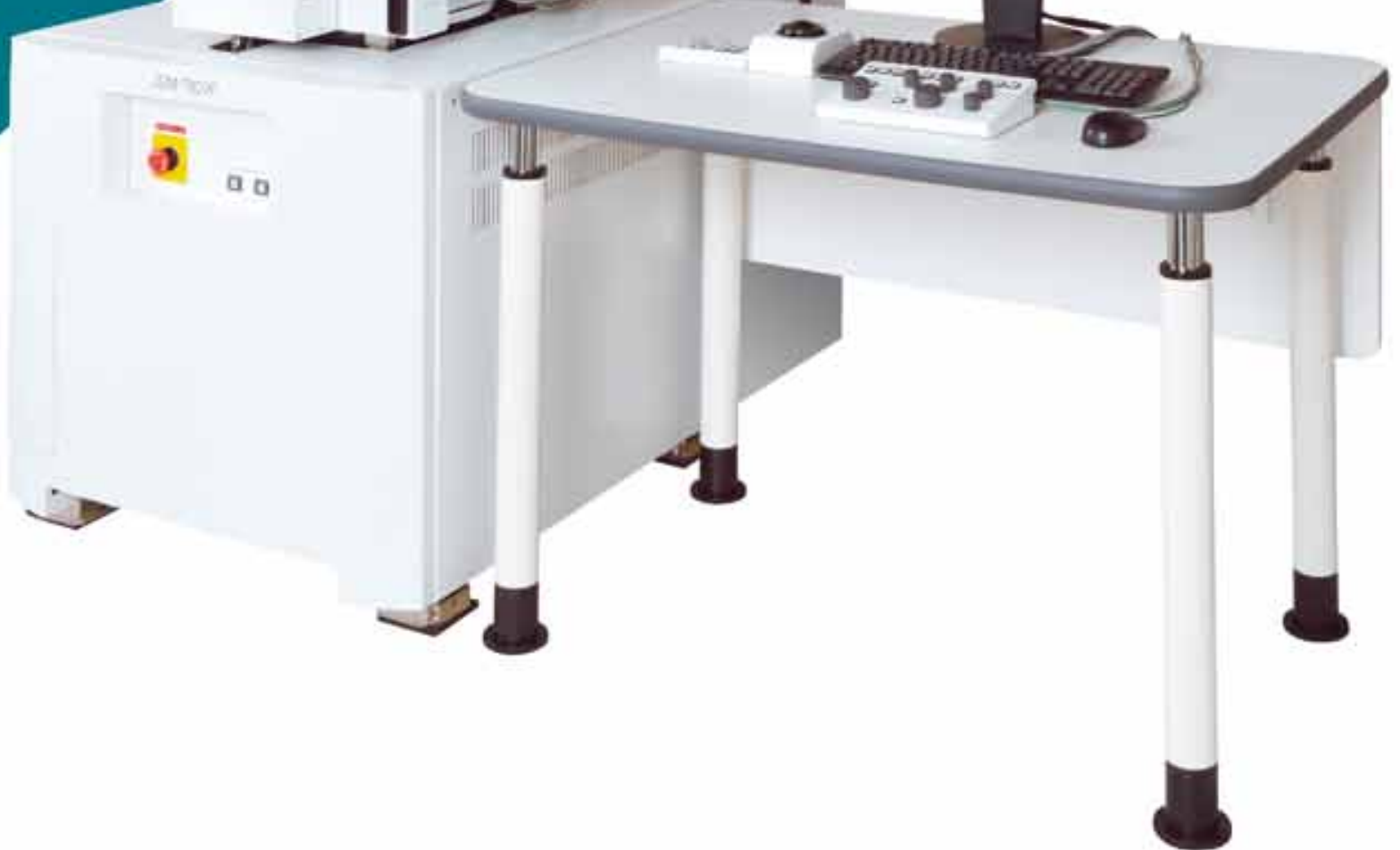

$\mathbf{0}$

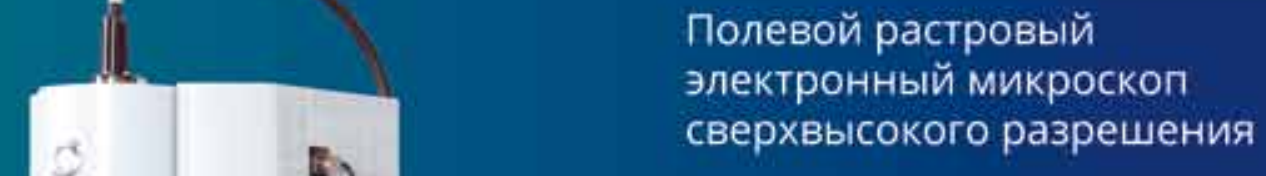

ООО «ДЖЕОЛ (РУС)» 
Всё же насколько доступны эти приборы? Можно ли назвать ориентировочную стоимость небольшого электронного микроскопа?

У нас есть установки, стоимость которых составляет порядка 100 тыс. долл. Согласитесь, это не такая большая сумма даже для относительно небольшой производственной компании.

\section{Не стоит бояться электронной} микроскопии, считать ее очень сложной или дорогой. Этот метод сегодня вполне доступен и может оказать большую помощь в условиях производства

При этом электронные микроскопы часто помогают выявлять дефекты, которые очень сложно, а иногда невозможно обнаружить с использованием обычного оптического микроскопа, в особенности с учетом микроминиатюризации электронных изделий. Это подтверждается тем, что некоторые наши заказчики использовали оптические приборы, но качество результатов контроля переставало их устраивать. Мы им предлагали перейти на электронную микроскопию, и таким образом они решали свои проблемы.

Если, тем не менее, компании приобретать даже такой небольшой микроскоп нецелесообразно, но нужно проверить несколько образцов или отдельную серию изделий, может ли она арендовать такое оборудование или воспользоваться услугами вашей компании по проведению исследований?

Во-первых, клиенты могут воспользоваться микроскопом, который расположен в нашем офисе. Здесь речь идет не о демонстрации оборудования, о которой я говорил ранее. Это платная услуга, в рамках которой наш заказчик может пользоваться данной установкой определенное время: допустим, два-три часа.

Во-вторых, мы сейчас начали переговоры, направленные на то, чтобы обеспечить заказчикам возможность брать наше оборудование в лизинг. Надеюсь, эти переговоры закончатся успешно, и у российских компаний появится возможность использовать различные наши приборы - как простые, так и самые передовые, - если приобретение такого оборудования в собственность для них нецелесообразно.

Также у нас есть услуга удаленного исследования. Клиент присылает свои образцы в наше подразделение, где есть необходимая установка, эти образцы загружаются в прибор, и клиенты могут проводить исследование в режиме онлайн.
Могут ли заказчики воспользоваться не только оборудованием в подразделениях JEOL, но и компетенциями специалистов компании? Ведь интерпретация результатов исследования - тоже весьма непростая задача, требующая большого опыта.

Такую услугу JEOL оказывает в Японии, США, некоторых других странах. К сожалению, пока Россия не входит в их число: у нас в Москве не такой большой офис. Однако в стратегии JEOL уделяется большое внимание развитию не только продаж оборудования, но и сервисов, позволяющих нашим клиентам решать их задачи. Поэтому мы в ООО «ДЖЕОЛ (рус)» тоже задумываемся об этом.

Вы рассказали о различных системах. На какое оборудование JEOL вы порекомендовали бы обратить внимание российским компаниям, работающим в области производства электроники, в первую очередь?

Наша линейка оборудования достаточно широкая, и, конечно, она не ограничивается тем, что я упомянул сегодня.

Безусловно, выбор той или иной системы зависит от конкретного производства, от тех задач, которые стоят перед компанией. Но я бы еще раз подчеркнул, что в современных условиях роста требований к качеству и надежности электронной аппаратуры и продолжающейся тенденции миниатюризации электронные микроскопы могут принести большую пользу. Мы рекомендуем производственным компаниям обратить внимание на небольшие электронные микроскопы, простые в использовании, сравнительно недорогие и способные с успехом применяться для контроля качества продукции и управления технологическими процессами.

Не стоит бояться электронной микроскопии, считать ее очень сложной или дорогой. Этот метод сегодня вполне доступен и может оказать большую помощь в условиях производства.

Сегодня, когда технологии развиваются очень быстро, для того чтобы обеспечивать конкурентоспособность продукции, просто необходимо знать о том, какое оборудование есть на рынке, и понимать, как оно может помочь в решении тех или иных задач. Мы готовы помогать российским компаниям в выборе как оборудования JEOL, так и услуг, предоставляемых нашей компанией, чтобы содействовать им в создании конкурентоспособной качественной продукции.

Спасибо за интересный рассказ.

С К. Саито беседовап Ю. Ковалевский 


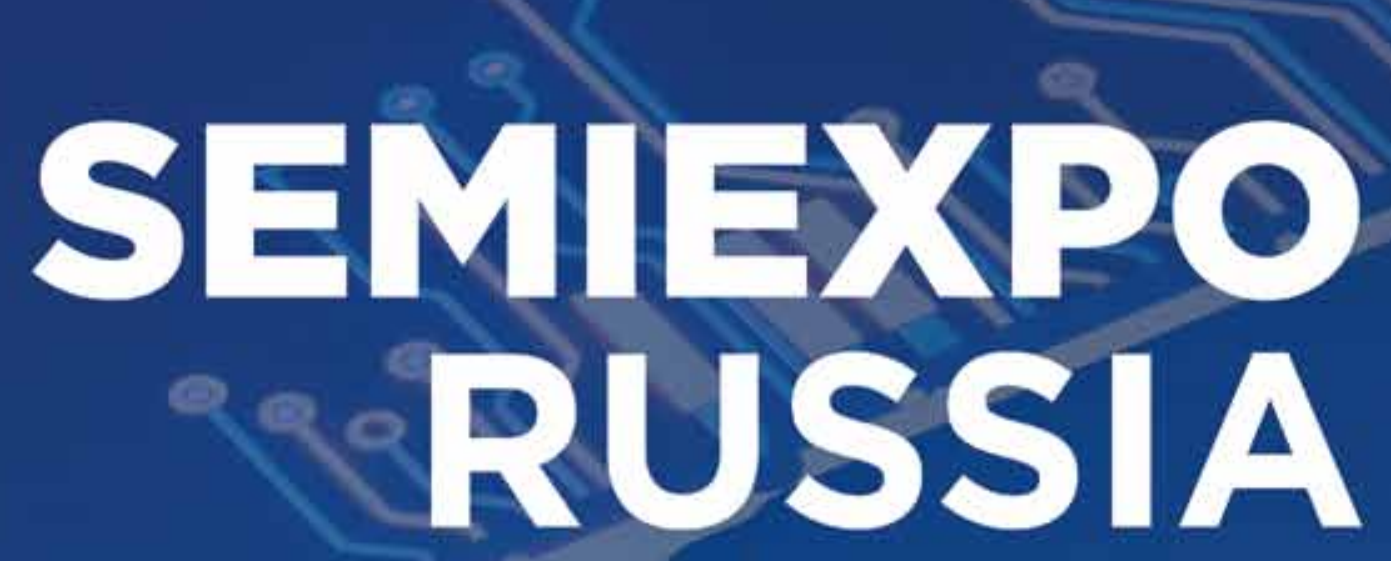

SEMIEXPO Russia объединяет международную специализированную выставку с двухдневной деловой программой, где ежегодно принимают участие руководители, эксперты, топ-менеджеры крупнейших компаний по микроэлектронике, представители органов государственной власти, научно-исследовательских институтов и международных ассоциаций.

\section{Программные мероприятия на SEMIEXPO Russia 2020}

SEMI Member Forum 2020

Международный MEMS Forum

Новый этап конкурса

«Инновационная радиоэлектроникар
Обзор карьерных возможностей и ежегодный День Талантов

Экспортные перспективы. Открытый диалог с зарубежными

рынками

Экспозиция кластеров из Европы и

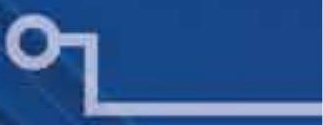

Азии

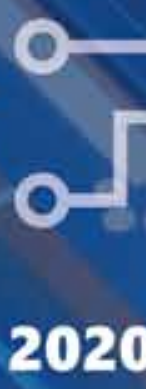

MOCKBA

ВКСПОЦЕНTP

9-10 ИЮНЯ 2020

\section{ВЫСТАВКА И КОНФЕРЕНЦИЯ}

\section{ПО ТЕХНОЛОГИЯМ, МАТЕРИАЛАМ,}

\section{СТАНДАРТАМ И ОБОРУДОВАНИЮ В}

\section{ОБЛАСТИ МИКРОЭЛЕКТРОНИКИ}

\section{wwW.semiexpo.ru}

(0) @semiexporussia 